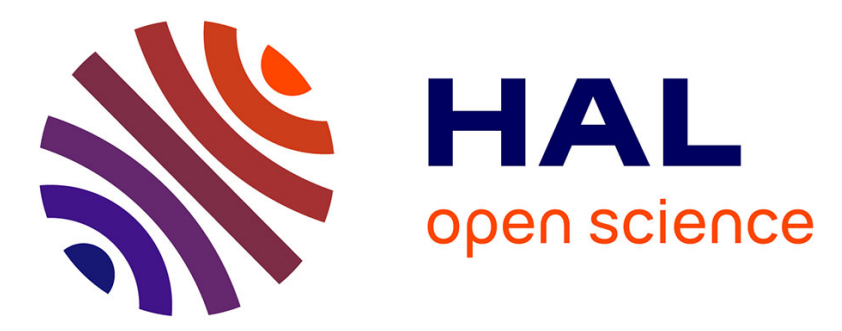

\title{
Cardiac response of the hydrothermal vent crab Segonzacia mesatlantica to variable temperature and oxygen levels
}

Stéphane Hourdez

\section{- To cite this version:}

Stéphane Hourdez. Cardiac response of the hydrothermal vent crab Segonzacia mesatlantica to variable temperature and oxygen levels. Deep Sea Research Part I: Oceanographic Research Papers, In press, 137, pp.57-65. 10.1016/j.dsr.2018.03.004 . hal-01763807

\section{HAL Id: hal-01763807 \\ https: / hal.sorbonne-universite.fr/hal-01763807}

Submitted on 11 Apr 2018

HAL is a multi-disciplinary open access archive for the deposit and dissemination of scientific research documents, whether they are published or not. The documents may come from teaching and research institutions in France or abroad, or from public or private research centers.
L'archive ouverte pluridisciplinaire HAL, est destinée au dépôt et à la diffusion de documents scientifiques de niveau recherche, publiés ou non, émanant des établissements d'enseignement et de recherche français ou étrangers, des laboratoires publics ou privés. 


\section{Cardiac response of the hydrothermal vent crab Segonzacia mesatlantica to variable temperature and oxygen levels}

Stéphane Hourdez ${ }^{1,2}$

${ }^{1}$ Centre National de la Recherche Scientifique, Adaptation and Biology of Invertebrates under Extreme Conditions, UMR7144, CNRS-UPMC, Station Biologique, 29680 Roscoff, France

${ }^{2}$ Sorbonne Université, Adaptation and Biology of Invertebrates under Extreme Conditions, UMR7144, CNRS-UPMC, Station Biologique, 29680 Roscoff, France

Phone: +33-298-29-2340

Fax: +33-298-29-2324

E-mail: hourdez@sb-roscoff.fr

Running title: Cardiac adaptation in a vent crab

Keywords: Hypoxia, Oxyregulation, Critical temperature, Critical oxygen concentration 


\section{Abstract}

Segonzacia mesatlantica inhabits different hydrothermal vent sites of the MidAtlantic Ridge where it experiences chronic environmental hypoxia, and highly variable temperatures. Experimental animals in aquaria at in situ pressure were exposed to varying oxygen concentrations and temperature, and their cardiac response was studied. $S$. mesatlantica is well adapted to these challenging conditions and capable to regulate its oxygen uptake down to very low concentrations (7.3-14.2 $\mu$ mol. $\left.1^{-1}\right)$. In $S$. mesatlantica, this capacity most likely relies on an increased ventilation rate, while the heart rate remains stable down to this critical oxygen tension. When not exposed to temperature increase, hypoxia corresponds to metabolic hypoxia and the response likely only involves ventilation modulation, as in shallowwater relatives. For $S$. mesatlantica however, an environmental temperature increase is usually correlated with more pronounced hypoxia. Although the response to hypoxia is similar at 10 and $20^{\circ} \mathrm{C}$, temperature itself has a strong effect on the heart rate and EKG signal amplitude. As in shallow water species, the heart rate increases with temperature. Our study revealed that the range of thermal tolerance for $S$. mesatlantica ranges from 6 through $21^{\circ} \mathrm{C}$ for specimens from the shallow site Menez Gwen $(800 \mathrm{~m})$, and from 3 through $19^{\circ} \mathrm{C}$ for specimens from the deeper sites explored $(2700-3000 \mathrm{~m})$. 


\section{Introduction}

Environmental exposure to hypoxia in aquatic habitats can be common (Hourdez, 2012). Near hydrothermal vents, oxygen levels are often low and highly variable both in space and in time. These conditions result from the chaotic mixing of the hydrothermal vent fluid, which is hot, anoxic, and often rich in sulfide, with the deepsea water, cold and usually slightly hypoxic. Oxygen and sulfide spontaneously react, decreasing further the amount of available oxygen in the resulting sea water. The presence of reduced compounds in the hydrothermal fluid is paramount to the local primary production by autotrophic bacteria at the base of the food chain in these environments. To reap the benefits of this high local production in an otherwise seemingly barren deep-sea at similar depths, metazoans must possess specific adaptations to deal with the challenging conditions, among which chronic hypoxia is probably one of the most limiting. All metazoans that have been studied to date indeed exhibit oxygen requirements comparable to those of close relatives that live in well-oxygenated environments (Childress and Mickel, 1985; Hourdez and Lallier, 2007).

A study of morphological adaptations in decapodan crustaceans revealed that, contrary to annelid polychaetes (Hourdez and Lallier, 2007), there is usually no increase in gill surface areas in vent decapods compared to their shallow-water relatives (Decelle et al., 2010). In the vent decapods however, the scaphognathite is greatly enlarged, suggesting an increased ventilatory capacity. In situ observations of vent shrimp in settings typified by different oxygen concentrations also indicated that these animals increased their ventilation rates under lower oxygen conditions (Decelle et al., 2010). This behavioral change is consistent with other decapods in which both the frequency and amplitude of scaphognathite beating are increased in response to hypoxia (see McMahon, 2001 and Whiteley and Taylor, 2015 for reviews).

The vent crab Bythograea thermydron Williams 1980 is able to maintain its oxygen consumption relatively constant over a wide range of oxygen concentrations (i.e. oxyregulation capability), down to much lower concentrations than the shallow water species for which this ability was studied (Gorodezky and Childress, 1994). The capacity to oxyregulate can involve different levels of regulation. At the molecular level, the functional properties of the hemocyanins (in particular their oxygen affinity) play a central role. Hemocyanins from decapods that inhabit deep-sea hydrothermal vents exhibit very high oxygen affinities, allowing the extraction of oxygen from 
hypoxic conditions (see Hourdez and Lallier, 2007 for a review). The properties of these blood oxygen carriers can also be affected by allosteric effectors contained in the hemolymph. Gorodezky and Childress (1994) showed that animals injected with thiosulfate, a byproduct of sulfide detoxification in the animals that increases hemocyanin affinity, allowed the crab to oxyregulate down to ever lower environmental oxygen concentrations. At the physiological level, adaptation to lower oxygen concentrations can involve ventilatory and cardio-circulatory responses (for a review, see McMahon, 2001). In the shallow water species studied to date, the circulatory response can be quite complex, involving modifications of the heart rate, stroke volume and peripheral resistance. Typically, decapods increase their ventilation (scaphognathite beating frequency and power), decrease their heart rate (bradycardia), and adjust the circulation of their hemolymph, decreasing its flow to digestive organs in favor of the ventral structures (McMahon, 2001).

The responses to variable oxygen levels involving modifications of heart parameters (contraction rate) and ventilation have however so far not experimentally been studied in hydrothermal vent species of crabs. We studied the cardiac response of the MidAtlantic Ridge (MAR) vent crab Segonzacia mesatlantica Williams 1988. This species has been collected at different sites from the MAR, with depths ranging from $850 \mathrm{~m}$ (Menez Gwen site) to $4080 \mathrm{~m}$ (Ashadze 1 site). To study the cardiac response to varying levels of environmental oxygen in S. mesatlantica, experimental animals were equipped with electrodes and their electrocardiograms (EKG) under different oxygen concentrations were recorded. As temperature affects oxygen demand as well, its effect on the EKG of the experimental crabs was also investigated.

\section{Materials and methods}

Animal collection

Specimens of the crab Segonzacia mesatlantica were collected on the hydrothermal vent sites Menez Gwen (37 $50^{\prime} \mathrm{N}, 31^{\circ} 31^{\prime} \mathrm{W}, 855 \mathrm{~m}$ water depth), Logatchev $\left(14^{\circ} 45.12^{\prime} \mathrm{N}, 44^{\circ} 58.71^{\prime} \mathrm{W}, 3050 \mathrm{~m}\right.$ water depth), and Irinovskoe $\left(14^{\circ} 20.01^{\prime} \mathrm{N}, 44^{\circ} 55.36^{\prime} \mathrm{W}, 2700 \mathrm{~m}\right.$ water depth), on the Mid-Atlantic Ridge. They were captured with the remotely operated vehicle (ROV) MARUM-Quest, deployed from the Research Vessel Meteor (Menez MAR M82/3 and M126 cruises). The animals were brought back to the surface in a thermally insulated 
box attached to the ROV and quickly transferred to a cold room $\left(5-8^{\circ} \mathrm{C}\right)$ before they were used for experiments. The few specimens from the shallow site (Menez Gwen) that were not used in the experimental system and were maintained at atmospheric pressure all survived for at least two weeks.

\section{Experimental system}

The experimental animals were fitted with three stainless-steel thin wire electrodes: two inserted on either side of the heart and the third in the general body cavity as a reference (Fig. 1A). The flexible leads where then glued directly onto the carapace to prevent the movements of the crabs from affecting the position of the implanted electrodes. Attempts to use the less-invasive infrared sensor simply attached to the shell (Depledge and Andersen, 1990, Robinson et al., 2009) proved unsuccessful on this species and on another vent crab, Bythograea thermydron (Hourdez, unpub. failure). The same sensor type also proved unsuccessful to measure scaphognathite beating frequency (possible penetration of the seawater into the sensor). The equipped animals were maintained in an anodized aluminum, custom-built, 500-ml pressure vessel (inside diameter $10 \mathrm{~cm}$ and $6.4 \mathrm{~cm}$ height) with a Plexiglas window that allowed regular visual inspection of the animals. The smaller specimens (LI-2 through LI6 and LI-10, see Table 1) were maintained in a smaller pressure vessel (inside diameter $3.5 \mathrm{~cm}$ and $5 \mathrm{~cm}$ height). The crabs were free to move inside the pressure vessel. During the experiment, the crabs usually remained calm, with some short activity periods. The water flow was provided by a HPLC pump (Waters 515), set to 3-5 $\mathrm{ml} \mathrm{min}^{-1}$, depending on the size of the specimen to yield an oxygen concentration decrease (compared to the inlet concentration) that was measurable with confidence. The pressure was regulated by a pressurerelief valve (Swagelok SS-4R3A) (Fig. 1B). Oxygen concentration in the inlet water was modulated by bubbling nitrogen and/or air with various flows. Oxygen concentrations are reported in $\mu$ mol..$^{-1}$ rather than partial pressures as these latter depend on the total pressure and are therefore difficult to compare between experiments run at different pressures. Oxygen concentration was measured directly after the pressure relief valve with an oxygen optode (Neofox, Ocean Optics). Three-way valves allowed water to flow either through the vessel 
containing the animal or through a bypass without affecting the pressure in the system. Oxygen consumption rate (in $\mu$ mol.h ${ }^{-1}$ ) was then simply calculated as the difference between these two values, taking the flow rate into consideration:

Oxygen consumption rate $=\left(\mathrm{O}_{2}\right.$ in $-\mathrm{O}_{2}$ out $) * \mathrm{WFR}$

where ' $\mathrm{O}_{2} \mathrm{in}^{\mathrm{\prime}}$ is the inlet oxygen concentration (in $\mu$ mol. $\mathrm{l}^{-1}$ ) measured with the bypass in place, ' $\mathrm{O}_{2}$ out' the oxygen concentration (in $\mu$ mol.l-1) measured when the water was flowing through the pressure vessel, and WFR the water flow rate (in $1 . h^{-1}$ ) controlled by the HPLC pump.

Temperature in the pressure vessel was controlled by immersion in a temperature-controlled water bath $\left(10\right.$ or $\left.20 \pm 0.2^{\circ} \mathrm{C}\right)$. Temperature ramping to study the effect of temperature on the heart rate was obtained by progressively increasing temperature in the water bath. We were interested in the crabs' response to rapid temperature variation and therefore chose a rate of about $1^{\circ} \mathrm{C}$ every 15 minutes. All experiments were run at a pressure equivalent to in situ pressure for the two sites ( 80 bars ( $8 \mathrm{MPa}$ ), equivalent to $800 \mathrm{~m}$ water depth for Menez Gwen and 270 bars (27 MPa) for the Logatchev and Irinovskoe sites).

\section{Recording of electrocardiograms (EKG)}

An electrical feed-through in the pressure vessel wall allowed the recording of the EKG of animals under pressure. We worked on a total of twelve specimens, including ten from Semyenov/Irinovskoe, and two from Menez Gwen (Table 1). Out of these twelve specimens, six were equipped with electrodes to monitor the electrical activity of their heart, including both Menez Gwen specimens. The voltage variations were recorded with a LabPro (Vernier) interface equipped with an EKG sensor (Vernier) for $30 \mathrm{~s}$ for each of the conditions. Voltage values were recorded every $1 / 100 \mathrm{~s}$. Recordings were made every 2-15 minutes, depending on the rate of change of the studied parameters. Specifically, temperature change was fast and recordings were made every 2-3 minutes, while changes in oxygen concentration were slower and recordings were made every 10-15 minutes. As the animals live in a highly variable environment, we were interested in the response to rapidly-changing conditions and did not give animals time to acclimate to various oxygen levels or temperature values. 
The crabs sometimes went through transient cardiac arrests (some as long as 20 seconds), a phenomenon also reported in shallow-water crabs, in particular in response to tactile and visual stimuli (e.g. Stiffler and Pritchard, 1972; Florey and Kriebel, 1974; DeFur and Mangum, 1979). Recordings comprising such arrests were not used for the calculation of heart rate. There was no apparent correlation between the conditions and the occurrence of the arrests, although they seemed to occur less at lower oxygen tensions (pers. obs.).

Changes in the parameters of the EKG (amplitude, shape) could reflect important modifications of cardiac output. We studied the effect of both temperature and oxygen concentration on the shape and amplitude of the EKG.

\section{Electrode implantation, recovery and effect of pressure}

Shortly after electrode implantation, the EKG was directly recordable at atmospheric pressure, although a bit erratic while manipulating the animal. For one of the shallower site crabs, the EKG was recorded for 4 hours at atmospheric pressure and $10^{\circ} \mathrm{C}$ in the closed experimental vessel. Once under stable conditions, the EKG quickly became regular, and its shape resembled that under pressure (data not shown). From an initial heart rate oscillating between 30 and 45 beats per minute (b.p.m.), the heart rate increased to 55 b.p.m. between 3.5 and 4 hours after implantation. After pressure was applied a bradycardia appeared (heart rate down to 35 b.p.m.), which lasted for about 1.5 hours before the heart rate returned to typical values for $10^{\circ} \mathrm{C}$ at 80 bars $(8 \mathrm{MPa} ; 60-70$ b.p.m., see below). Similarly, animals from the Irinovskoe or Logatchev sites (2700$3050 \mathrm{~m}$ depth) and acclimated to their in situ pressure, exhibit transient bradycardia when exposed to lowered pressure. Within a few minutes, the animals stabilized their heart rate to values greater than simulated in situ pressure values. At pressure values lower than 150 bars (15 mPa), the heart rate remained relatively stable (see supplementary material S1). Upon return to the in situ pressure value, the heart rate rapidly returned to the initial value. Consequently, all experiments were run at pressures equivalent to that of the depth at which they were captured and, after re-pressurization, the animals were given 8-12 hours of recovery before experiments were initiated. 


\section{Determination of curve parameters}

We used curve fitting to determine key values for the heart rate and oxygen consumption as a function of oxygen concentration. In particular, the critical oxygen concentration at which oxygen consumption or heart rate drops can be relatively subjective or its determination strongly dependent on the relatively small number of data points below that value. When the critical oxygen concentration is small (as it is the case for $S$. mesatlantica, see results), very few data points can be obtained below that value. Instead, we used the equation:

$$
Y=a * \frac{X-c}{1+b *(X-c)}
$$

where $\mathrm{X}$ is the oxygen concentration, $\mathrm{Y}$ is the physiological parameter (heart rate or oxygen consumption rate), $b$ is a steepness coefficient, the ratio $a / b$ is the value at plateau ( $\mathrm{X}$ infinite), and $\mathrm{c}$ is the intercept of the curve with the $\mathrm{X}$-axis. The curve fitting parameters $a, b$, and c were obtained with the software JMP11, based on an exploration of possible values for the parameters a, b, and c, and the best values were determined by minimizing the difference between the observed (experimental) and expected values (based on the curve equation). Because of the very steep drop of both heart rate and oxygen consumption rate (see Fig. 3), the intercept $\mathrm{c}$ is hereafter referred to as the critical oxygen concentration.

\section{Results}

\section{Oxygen consumption rates}

The oxygen consumption rates (in $\mu$ mole $\mathrm{O}_{2}$ per hour) were measured for all 12 specimens (Table 1, Fig. 2). With a size range of 0.4-41.5 g wet weight, the oxygen consumption rate increases with an allometry coefficient of $0.48(p=2.8$ $10^{-8}$ ). The sex of the animals does not have a significant effect on the regression (ANCOVA, $p=0.1784$ ). The oxygen consumption rates for the two specimens from Menez Gwen (800 m depth) do not differ markedly from the specimens from the other sites (2700-3050 m depth), and fall within the $95 \%$ confidence interval established for the ten specimens from the deeper sites. 


\section{Effect of oxygen concentration on heart rate and oxygen consumption}

In all investigated specimens, both the oxygen consumption rates and heart rates follow the same pattern. For all specimens equipped with electrodes $(n=6)$, oxygen concentration does not affect the heart rate over most of the range of concentrations, until a critical low concentration is reached (Fig. 3). Below that concentration, the heart rate and the oxygen consumption both drop sharply. The oxygen consumption reaches zero at oxygen concentrations ranging from 7.3 to $9.9 \mu$ mole. $\mathrm{l}^{-1}$ for the deeper sites and 11.3-14.2 $\mu$ mole. $\mathrm{l}^{-1}$ for the shallower site (Table 1 ). At $10^{\circ} \mathrm{C}$, the heart rate typically oscillates between 61 and 68 beats per minute (b.p.m.) while it usually varies between 90 and 108 b.p.m. at $20^{\circ} \mathrm{C}$ for the specimens from the shallower site (Supplementary data Fig. S2). For the specimens from the deeper sites, the heart rate at $10^{\circ} \mathrm{C}$ is higher (72.3-81.5 b.p.m.; Table 1) than that of the specimens from the shallower site (62.5 and 69.0; Table 1). Although the heart rate tends to decrease with increasing wet weight, the correlation is not significant (log/log transform linear correlation $p=0.15)$.

\section{Effect of temperature}

Temperature affects the beating frequency of the heart for the three specimens tested (Fig. 4). The Arrhenius plot for the two LI individuals shows a biphasic curve between $3^{\circ} \mathrm{C}$ and the Arrhenius break point at $19^{\circ} \mathrm{C}$. At a temperature higher than $19^{\circ} \mathrm{C}$ or lower than $3^{\circ} \mathrm{C}$, the heart rate is more variable and drops sharply in warmer water, indicating that $19^{\circ} \mathrm{C}$ is the upper temperature limit for this species. Below $3^{\circ} \mathrm{C}$ (normal deep-sea temperature in the area), the heartbeat is also irregular, possibly indicating a lower temperature limit for this species. This phenomenon is also observed at $6^{\circ} \mathrm{C}$ for the specimen from the shallower site (normal deep-sea water temperature $8^{\circ} \mathrm{C}$ for this area). In addition to the upper and lower breakpoints, there is an inflection point for the two deeper specimens at $10.7^{\circ} \mathrm{C}$ (Fig. 4). The colder part of the curve has a slope of $c a .4$, while the upper part of the curve has a slope of 1.7-2. This inflection point could also be present for the shallower specimen but the temperature range below that value is too short to allow a proper estimate of the slope. 


\section{Modifications the EKG characteristics}

In addition to the beating frequency, temperature also affects the overall shape of the EKG (Fig. 5). It is characterized by two large peaks at $12^{\circ} \mathrm{C}$, in addition to a smaller one preceding the large peaks. The second large peak increases in height in respect to the first one as temperature increases. At $16^{\circ} \mathrm{C}$, the two peaks have approximately the same amplitude, and fuse completely at higher temperatures. The height of the second peak increases with temperature while that of the first peak remains unchanged up to $16^{\circ} \mathrm{C}$. Beyond that temperature, the height of the fused peaks keeps increasing at a rate similar to that of the second peak, suggesting it is the contribution of that second peak that is responsible for the changes in amplitude. Beyond $20^{\circ} \mathrm{C}$, the amplitude tends to level off or decrease slightly.

Over most of the range tested, oxygen concentration does not seem to affect the amplitude of the EKG (Fig. 6). Below $25 \mu$ mole. ${ }^{-1}$ of oxygen, however, the amplitude of the EKG drops sharply. This phenomenon occurs at lower oxygen concentrations than the drop in heart rate $\left(32 \mu\right.$ mole. $l^{-1}$ at this temperature for the same animal). At values below $25 \mu$ mole. $l^{-1}$ of oxygen, the shape of the EKG is also significantly affected (Fig. 7), with a drastic decrease of the second peak height, to the point it may completely disappear (Fig. 7, $17 \mu$ mole. $^{-1}$ oxygen inset). Upon return to oxygen concentrations greater than $25 \mu$ mole. $\mathrm{l}^{-1}$, the EKG returns to its pre-hypoxia characteristics (Fig. 7, $62 \mu$ mole.l-1 oxygen inset).

\section{Discussion}

\section{Oxygen consumption rate}

As expected, the oxygen consumption rates increase with increasing size, and this increase follows an allometry with coefficient 0.48 . This coefficient is in the low end of the range reported for other marine crustaceans (Vidal and Whiteledge, 1982). This value is lower to that reported for the shore crab Carcinus maenas (0.598; Wallace, 1972). There is evidence that the allometry of metabolism is linked to activity, metabolic rate, and habitat (Carey et al., 2013). Compared to the other hydrothermal vent species studied to date, Bythograea thermydron, the rate is very similar for the large animals (Mickel and Childress, 
1982b). Mickel and Childress (1982) however report an allometry coefficient not significantly different from 1.0 , although the total size range in their study was reportedly not sufficient (20.0-111.4 g wet weight) to obtain reliable data. The wet weights in our study cover two orders of magnitude (0.4-41.5 g wet weight), yielding a more reliable allometry coefficient. The oxygen consumption rates are also similar to other deep-sea and shallow-water crustaceans (Childress and Mickel, 1985). Deciphering the meaning of the small allometry coefficient will require a comparative study of crabs closely related to Segonzacia and inhabiting different habitats.

\section{Changes in the EKG shape characteristics}

In decapod crustaceans, the heartbeat is initiated within the cardiac ganglion, where a small number of pacemaker neurons control this heartbeat (for a review, see McMahon, 1999). Wilkens (1993) reports that it is maintained in isolated hearts, provided that the partial pressure of oxygen is sufficient. The overall shape of the EKG resembles that recorded for Bythograea thermydron, another hydrothermal vent crab studied by Mickel and Childress (1982) and other, shallow-water, crabs (Burnovicz et al., 2009). For B. thermydron, the authors did not consider changes in amplitude as a function of pressure because the amplitude seemed to be affected by the time elapsed since electrode implantation and pressure affected the electrical connectors in the vessel. In the present study however, pressure remained unchanged and changes in amplitude of the EKG were accompanied by modifications of the shape of the EKG, suggesting the amplitude changes were not artifacts.

In our recordings, the EKG pattern clearly comprises two major peaks that fuse at temperatures greater than $16^{\circ} \mathrm{C}$. The relationship between each on the peaks and its potential physiological role (pacemaker, cardiac output control) would be an interesting avenue to explore but the need to work under pressure for $S$. mesatlantica renders this line of study difficult in this species.

\section{Effect of temperature}

For the Menez Gwen animals, the Arrhenius plot of the heart rate revealed that the normal range of functioning for this species lies between $6^{\circ} \mathrm{C}$ and $21^{\circ} \mathrm{C}$ at 80 
bars ( $8 \mathrm{Mpa}$ ). The temperature of the deep-sea water at these depths is close to $8^{\circ} \mathrm{C}$, and the animals are then unlikely to encounter limiting conditions in the colder end of the range. Hydrothermal fluid, mixing with the deep-sea water, can however yield temperatures far greater than the upper end of the range, likely limiting the distribution of the crabs in their natural environment, in combination with other limiting factors (e.g. oxygen, sulfide). The upper temperature is however lower than that reported for B. thermydron, the eastern Pacific relative of $S$. mesatlantica (Mickel and Childress, 1982), although pressure is very likely to affect the physiology of the animals. These authors report that at $238 \mathrm{~atm}$ (23.8 $\mathrm{MPa}$, corresponding to their typical environmental pressure) $B$. thermydron is capable of surviving $1 \mathrm{~h}$ at $35^{\circ} \mathrm{C}$ but died when exposed for the same duration at 37.5 or $40^{\circ} \mathrm{C}$. Animals maintained at $238 \mathrm{~atm}$ and $30^{\circ} \mathrm{C}$ however exhibited a very disrupted EKG, and three of the five experimental animals died within 2 hours. Contrary to the East Pacific Rise species B. thermydron, the MidAltantic Ridge species S. mesatlantica is found living as shallow as $800 \mathrm{~m}$. Animals collected from this shallow site can survive at least 2 weeks at atmospheric pressure (provided they are kept in a cold room at $5-8^{\circ} \mathrm{C}$ ), suggesting that they do not experience disruptions of the heart function as severe as those observed in B. thermydron at 1 atm (Mickel and Childress, 1982). This hypothesis is supported by the observations performed at $1 \mathrm{~atm}$ on freshly collected animals that showed a normal aspect of the EKG (see 'Materials and Methods' section). S. mesatlantica is also found at greater depths on other sites of the Mid-Atlantic Ridge (down to at least 3000 m depth). Our work on specimens from these deeper sites did not reveal an extended upper temperature tolerance, on the contrary the Arrhenius breakpoint is $2^{\circ} \mathrm{C}$ lower for these animals $\left(19^{\circ} \mathrm{C}\right.$ for the two specimens tested instead of $21^{\circ} \mathrm{C}$ for the shallower site specimen). The same shift is observed for the low temperatures: the lower thermal tolerance is about $6^{\circ} \mathrm{C}$ for the shallow water specimen and about $3^{\circ} \mathrm{C}$ for the deeper ones. Overall, it seems the total thermal range is about $16^{\circ} \mathrm{C}$, with a shift towards colder temperature in deeper specimens.

The absolute heart rates recorded for our species do not differ greatly from other crabs of similar sizes for comparable temperatures. They are very similar to those obtained for the shore crab Carcinus maenas (Ahsanullah and Newell, 
1971; Giomi and Pörtner, 2013), the mud crab Panopeus herbsti, and the blue crab Callinectes sapidus (DeFur and Mangum, 1979). Some other species have much greater heart rates (235 b.p.m. for Hemigrapsus nudus at $18^{\circ} \mathrm{C}$ ) or much lower values (82 b.p.m. for Libinia emarginata at $25^{\circ} \mathrm{C}$; DeFur and Mangum, 1979).

The characteristics of the EKG pattern also changed with temperature. Although the amplitude of the signal for the first large peak remained unchanged, that of the second large peak increased linearly with temperature up to the maximal temperature. This could reflect modifications of the cardiac output in $S$. mesatlantica. In Cancer magister and C. productus, the cardiac output declines but an increased oxygen delivery to the organs is possible through a concomitant decrease of hemocyanin oxygen affinity (Florey and Kriebel, 1974). There is however no study linking EKG parameters to cardiac output in crustaceans.

\section{Oxygen and capacity limited thermal tolerance (OCLTT)}

The concept of oxygen and capacity limited thermal tolerance (OCLTT) was developed to explain the observations on temperature tolerance (Frederich and Pörtner, 2000; Pörtner, 2001). The authors hypothesized that a mismatch between oxygen demand and oxygen supply results from limited capacity of the ventilatory and the circulatory systems at temperature extremes. They argue that limitations in aerobic performance are the first parameters that will affect thermal tolerance. In Segonzacia mesatlantica, the Arrhenius plot of the heart rate exhibits a biphasic profile for these animals from the deeper sites, with an inflection point at $10.7^{\circ} \mathrm{C}$. In the temperate eurythermal crab Carcinus maenas, Giomi and Pörtner (2013) report a similar observation. The authors interpret this inflection as the pejus temperature, beyond which hypoxemia sets in until the critical temperature (onset of anaerobic metabolism). This would then indicate an optimal temperature range of $3-10.7^{\circ} \mathrm{C}$ from $S$. mesatlantica, beyond which the exploitation of hemocyanin-bound oxygen reserve delays the onset of hypoxemia. Contrary to the $C$. maenas hemocyanin, however, the hemocyanin from $S$. mesatlantica does not release oxygen in response to increased temperature, a lack of temperature sensitivity that is found in other 
hydrothermal vent crustacea hemocyanins (Chausson et al., 2004, Hourdez and Lallier, 2007).

\section{Effect of oxygen concentration}

At hydrothermal vents, temperature and oxygen concentration are negatively correlated (Johnson et al., 1986). The animals therefore need to extract even more oxygen to meet their metabolic demand when it is less abundant in their environment. The conditions also fluctuate rapidly and animals need to respond quickly to the chronic hypoxia they experience.

In most crustaceans, exposure to hypoxia below the critical oxygen tension induces a bradycardia, coupled with a redirection of the hemolymph from the digestive organs towards ventral structures (McMahon, 2001). In our species, the heart rate remained relatively stable over a very wide range of oxygen concentrations and only dropped below a critical oxygen concentration similar to that of the oxygen consumption. This critical oxygen concentration ranges from 7.3 to $14.2 \mu$ mol. $^{-1}$. These values are greater than the half-saturation oxygen tension of the hemocyanin $\left(\mathrm{P}_{50}=3.7 \mu \mathrm{mol.} \mathrm{l}^{-1}\right.$ at $15^{\circ} \mathrm{C}$, Chausson et al., 2004), suggesting that hemocyanin is not the limiting factor in the failure of oxyregulation at lesser environmental oxygen concentrations. Diffusive and convective (ventilation) processes are likely to limit oxygen uptake. However, the ability to maintain a stable heart rate down to low environmental tensions, along with the high affinity hemocyanin, likely accounts for the very low critical oxygen concentration observed for the vent crabs (this study; Mickel and Childress, 1982) compared to their shallow water relatives (e.g. 100-130 $\mu \mathrm{mol}^{-\mathrm{l}^{-1}}$ in Carcinus maenas; Taylor, 1976).

The EKG amplitude and shape does not change in response to oxygen concentration variations over most of the tested range. Below the critical concentration however, both the amplitude and the presence of the second large peak are affected. This suggests that, although the pacemaker activity remains, the heart either contracts less strongly or does not contract at all. As a result, the hemolymph does not circulate and the animal is unable to regulate its oxygen uptake. As for shallow-water species, the animals are able to survive anoxia. In the crabs Cancer magister and C. productus, this can be tolerated for up to $1 \mathrm{hr}$ 
(Florey and Kriebel, 1974). Our experimental crabs were also maintained for the same duration below their ability to oxyregulate, a time during which, once oxygen reserves were depleted, they had to rely on anaerobiosis. During that time, the heart rate varied greatly (Fig. 7), possibly indicating attempts to reestablish oxygen uptake.

Measuring the modifications of blood flow to different parts of the body was unfortunately not feasible inside the pressure vessels. Similarly, we were not able to measure ventilation rate or ventilation flow in our set-up. However, the ability to oxyregulate while maintaining a stable heart rate (neither tachycardia nor bradycardia) strongly suggests that ventilation increases under hypoxic conditions as it does in for example in C. maenas (Taylor, 1976; Giomi and Pörtner, 2013). In the hydrothermal vent shrimp Alvinocaris komaii, animals observed in situ in environments characterized by lower oxygen tensions exhibited a higher ventilation rate (Decelle et al., 2010), as typical of other decapods (see McMahon, 2001). Although not directly observed in $S$. mesatlantica, a similar response is very likely.

\section{Conclusion}

As all marine invertebrates, Segonzacia mesatlantica can experience hypoxia through both environmental exposure and as a consequence of increased metabolic consumption during exercise. Unlike most marine invertebrates however, environmental hypoxia is chronic -and possibly continuous- for this species. $S$. mesatlantica, like its East Pacific Rise congener Bythograea thermydron, is well adapted to these challenging conditions and capable regulate of regulating its oxygen uptake down to very low environmental tensions. In S. mesatlantica, this capacity most likely relies on an increased ventilation rate, while the heart rate remains stable. This is probably helped by the increased ventilatory capacity found in the vent species compared to their shallow water relatives (Decelle et al., 2010). When not exposed to temperature increase, hypoxia corresponds to metabolic hypoxia and the response only involves ventilation modulation (and possibly circulatory adjustments). For this species, however, a temperature increase is usually correlated with more pronounced hypoxia. Although the response to hypoxia is similar at 10 and $20^{\circ} \mathrm{C}$, temperature itself has a strong effect on the heart rate and the characteristics of the EKG. It would 
be interesting to investigate whether the lack of temperature sensitivity (Chausson et al., 2004) impacts the cardiac output response to temperature in comparison to nonhydrothermal vent endemic species.

\section{Acknowledgements}

All the work described here would not have been possible without the skills and help of the ROV MARUM-Quest crew, not only for animal collections but also for fixing a broken fiber optics cable used in my system: many thanks to a great crew. The crew of the RV Meteor has also been very helpful on board. I would also like to thank Nicole Dubilier, chief scientist, for inviting me on this cruise and for exciting scientific discussions. The modular pressure vessels used in this study were based with permission on a design by Raymond Lee. I would like to thank Jim Childress for very insightful discussions. This research was supported in part by the European Union FP7 Hermione programme (Hotspot Ecosystem Research and Man's Impact on European Seas; grant agreement no. 226354), and by the Region Bretagne HYPOXEVO grant. The German Research Foundation (DFG) and the DFG Cluster of Excellence "The Ocean in the Earth System" at MARUM, Bremen (Germany) are acknowledged for funding and support of the research cruise with the RV Meteor (MenezMar M82/3 and M126) and ROV MARUM-Quest.

The author declares that he has no competing interests.

\section{References}

Ahsanullah, M., Newell, R.C., 1971. Factors affecting the heart rate of the shore crab

Carcinus maenas (L.). Comp. Biochem. Physiol. A 39, 277-287.

https://doi.org/10.1016/0300-9629(71)90084-3

Burnovicz, A., Oliva, D. Hermitte, G., 2009. The cardiac response of the crab

Chasmagnathus granulatus as an index of sensory perception. J. Exp. Bio. 212, 313-

324. doi: 10.1242/jeb.022459 
Carey, N., Sigwart, J.D., Richards, J.G., 2013. Economies of scaling: More evidence that allometry of metabolism is linked to activity, metabolic rate and habitat. J. Exp. Mar. Biol. Ecol. 439, 7-14. https://doi.org/10.1016/j.jembe.2012.10.013

Chausson, F., Sanglier, S., Leize, E., Hagège, N., Bridges, C.R., Sarradin, P.-M., Shillito, B., Lallier, F.H., Zal, F., 2004. Respiratory adaptations to the deep-sea hydrothermal vent environment: the case of Segonzacia mesatlantica, a crab from the Mid-Atlantic Ridge. Micron 35, 31-41. https://doi.org/10.1016/j.micron.2003.10.010

Childress, J.J., Mickel, T.J., 1985. Metabolic rates of animals from hydrothermal vents and other deep-sea habitats. Biol. Soc. Wash. Bull. 6, 249-260.

Decelle, J., Andersen, A.C., Hourdez, S., 2010. Morphological adaptations to chronic hypoxia in deep-sea decapod crustaceans from hydrothermal vents and cold-seeps. Mar. Biol. 156(7), 1259-1269. https://doi.org/10.1007/s00227-010-1406-8

DeFur, P.L., Mangum, C.P., 1979. The effects of environmental variables on the heart rates of invertebrates. Com. Biochem. Physiol. A 62(2), 283-294.

https://doi.org/10.1016/0300-9629(79)90058-6

Depledge, M.H., Andersen, B.B., 1990. A computer-aided physiological monitoring system for continuous, long-term recording of cardiac activity in selected invertebrates. Comp. Biochem. Physiol. A 96(4), 473-477. https://doi.org/10.1016/0300-9629(90)90664-E

Florey, E., Kriebel, M.E., 1974. The effects of temperature, anoxia and sensory stimulation on the heart rate of unrestrained crabs. Comp. Biochem. Physiol. A 48(2), 285-300. https://doi.org/10.1016/0300-9629(74)90709-9

Frederich, M., Pörtner, H.O., 2000. Oxygen limitation of thermal tolerance defined by cardiac and ventilatory performance in spider crab, Maja squinado. Am. J. Physiol. Regul. Integr. Comp. Physiol. 279(5), R1531-R1538. https://doi.org/10.1152/ajpregu.2000.279.5.R1531 
Giomi, F., Pörtner, H.O., 2013. A role for haemolymph oxygen capacity in heat tolerance of eurythermal crabs. Frontiers Physiol. 4, 110. https://www.frontiersin.org/articles/10.3389/fphys.2013.00110/full

Gorodezky, L.A., Childress, J.J., 1994. Effects of sulfide exposure history and hemolymph thiosulfate on oxygen-consumption rates and regulation in the hydrothermal vent crab Bythograea thermydron. Mar. Biol. 120, 123-131. https://doi.org/10.1007/BF00381948

Hourdez, S. 2012. Hypoxic environments. In Life at Extremes: Environments, Organisms and Strategies for Survival (ed. E. M. Bell), pp. 438-453. Oxfordshire: CAB International.

Hourdez, S., Lallier, F.H., 2007. Adaptations to hypoxia in hydrothermal vent and cold-seep invertebrates. Rev. Environ. Sci. Biotech. 6, 143-159. https://doi.org/10.1007/s11157-006-9110-3

Jonhson, K.S., Beehler, C.L., Sakamoto-Arnold, C.M. and Childress, J.J., 1986. In situ measurements of chemical distributions in a deep-sea hydrothermal vent field. Science 231(4742), 1139-1141. DOI: 10.1126/science.231.4742.1139

McMahon, B.R., 1999. Intrinsic and extrinsic influences on cardiac rhythms in crustaceans. Comp. Biochem. Physiol. A 124, 539-547. https://doi.org/10.1016/S1095-6433(99)00147-6

McMahon, B.R., 2001. Respiratory and circulatory compensation to hypoxia in crustaceans. Respir. Physiol. 128, 349-364. https://doi.org/10.1016/S00345687(01)00311-5

Mickel, T.J., Childress, J.J., 1982a. Effects of pressure and temperature on the EKG and heart rate of the hydrothermal vent crab Bythograea thermydron (Brachyura). Biol. Bull. 162, 70-82. https://doi.org/10.2307/1540971 
Mickel, T.J., Childress, J.J., 1982b. Effects of temperature, pressure, and oxygen concentration on the oxygen consumption rate of the hydrothermal vent crab Bythograea thermydron (Brachyura). Physiol. Zool. 55, 199-207. https://doi.org/10.1086/physzool.55.2.30155856

Pörtner, H.O., 2001. Climate change and temperature-dependent biogeography: oxygen limitation of thermal tolerance in animals. Naturwissenschaften 88, 137-146.

- Robinson, N.J., Thatje, S., Oseforth, C., 2009. Heartbeat sensors under pressure: a new method for assessing hyperbaric physiology. High Pres. Res. iFirst, 1-9. https://doi.org/10.1080/08957950903076398

Stiffler, D.F., Pritchard, A.W., 1972. A comparison of in situ and in vitro responses of crustacean hearts to hypoxia. Biol. Bull. 143, 247-255.

Taylor, A.C., 1976. The respiratory responses of Carcinus maenas to declining oxygen tension. J. Exp. Biol. 65, 309-322.

Vidal, J., Whiteledge, T.E., 1982. Rates of metabolism of planktonic crustaceans as related to body weight and temperature of habitat. J. Plankton Res. 4(1), 77-84. https://doi.org/10.1093/plankt/4.1.77

Wallace, J.C., 1972. Activity and metabolic rate in the shore crab Carcinus maenas (L.). Comp. Biochem. Physiol. 41A, 523-533. https://doi.org/10.1016/03009629(72)90010-2

Whiteley, N.M., Taylor, E.W., 2015. Responses to environmental stresses: oxygen, temperature, and $\mathrm{pH}$. Chapter 10. In: The Natural History of Crustaceans. Growth, Moulting and Physiology (Vol 10). Ed Chang ES \& Thiel M. 320-358.

Wilkens, J.L., 1993. Re-evaluation of the stretch sensitivity hypothesis of crustacean hearts: hypoxia, not lack of stretch, causes reduction in the heart rate of isolated 
hearts. J. Exp. Biol. 176, 223-232. 
1 Table 1: Collection, morphological and physiological characteristics of the experimental animals at $10^{\circ} \mathrm{C}$ and under in situ pressure.

2 Animals LI-2 through LI-6 and LI-10 were too small for adequate electrode implantation.

\begin{tabular}{lllccccc}
\cline { 2 - 7 } Specimen & $\begin{array}{l}\text { Depth of } \\
\text { capture }(\mathrm{m})\end{array}$ & $\begin{array}{l}\text { Sex } \\
\text { ID }\end{array}$ & $\begin{array}{l}\text { Size }^{\mathrm{a}} \\
(\mathrm{mm})\end{array}$ & $\begin{array}{l}\text { Wet } \\
\text { weight }(\mathrm{g})\end{array}$ & $\begin{array}{l}\text { Heart rate } \\
(\text { b.p.m. })\end{array}$ & $\begin{array}{l}\text { Resp. rate } \\
\left(\mathrm{mmol}^{-1}\right)\end{array}$ & $\begin{array}{l}\text { Critical } \\
\text { conc. }\end{array}$ \\
MG-1 & 800 & $\mathrm{O}$ & 51 & 41.5 & 69.0 & 41.1 & 14.2 \\
MG-2 & 800 & $\mathrm{~F}$ & 34 & 24.2 & 62.5 & 35.4 & 11.3 \\
LI-1 & 3050 & $\mathrm{M}$ & 27 & 7.7 & 81.1 & 16.6 & 9.8 \\
LI-2 & 3050 & $\mathrm{M}$ & 13 & 0.9 & No data & 5.3 & 8.8 \\
LI-3 & 3050 & $\mathrm{M}$ & 21 & 3.0 & No data & 11.8 & 9.9 \\
LI-4 & 3050 & $\mathrm{M}$ & 17 & 1.7 & No data & 8.8 & 8.9 \\
LI-5 & 3050 & $\mathrm{M}$ & 7.5 & 0.2 & No data & 3.3 & 8.9 \\
LI-6 & 3050 & $\mathrm{M}$ & 12 & 0.6 & No data & 5.5 & 9.2 \\
LI-7 & 3050 & $\mathrm{~F}$ & 23 & 3.6 & 81.5 & 12.3 & 8.9 \\
LI-8 & 2700 & $\mathrm{~F}$ & 53 & 39.1 & 74.8 & 47.2 & nd \\
LI-9 & 2700 & $\mathrm{~F}$ & 31 & 10.1 & 72.3 & 31.4 & 7.9 \\
LI-10 & 3050 & $\mathrm{M}$ & 12 & 0.4 & No data & 6.3 & 7.3
\end{tabular}

3 MG: Individuals from the Menez Gwen site; LI: Individuals from the Logatchev or Irinovskoe sites; a: Cephalothorax width; b: average

4 value for the plateau area of the graph; nd: not determined. 


\section{Figures legends}

Figure 1: Experimental set-up. (A) Electrode implantation on an experimental animal (cephalothorax width about $50 \mathrm{~mm}$ ). (B) Flow-through pressure vessel, control of oxygen concentration, and position of oxygen optode. The bypass line allows the isolation of the vessel and the measurement of oxygen concentration in the inlet water.

Figure 2: Oxygen consumption rates (oxygen cons.; in $\mu \mathrm{mol}^{-1} \mathrm{l}^{-1} \cdot \mathrm{h}^{-1}$ ) as a function of wet weight in grams (WW) for all specimens $(n=12$, see table 1 for specimens characteristics). The linear regression has the equation log(Oxygen cons. $)=0.48 * \log (\mathrm{WW})+0.87$, and a correlation coefficient $\mathrm{r}^{2}=0.959(\mathrm{p}<0.001)$.

Figure 3: Oxygen consumption rate (open diamonds) and heart rate (black diamonds) in response to oxygen levels in the pressure vessel. Conditions: 270 bars $\left(27 \mathrm{MPa}\right.$ ) of pressure at $10^{\circ} \mathrm{C}$ for specimen LI-1 (see Table 1 for specimen characteristics). The curves were fit to the datapoints as described in the Materials and methods section.

Figure 4: Arrhenius plot of temperature-induced changes of the heart rate (HR) of $\boldsymbol{S}$. mesatlantica for three specimens under in situ pressure. 1000/ K: reciprocal temperature in Kelvin (multiplied by 1000 for ease of reading). See Table 1 for specimens characteristics. The Arrhenius breakpoint, inflection point in the relationship, and slope values on either side of this point are also indicated.

Figure 5: Modifications of EKG characteristics in response to temperature under 80 bars (8 MPa) of pressure and at non-limiting oxygen concentrations (50-100 mol. $^{-1}$ ). Open diamonds: amplitude of the first peak in the EKG; black squares: amplitude of the second peak. Note that at temperature values greater than $16^{\circ} \mathrm{C}$, the two peaks fuse, and only the black symbols are used. Each datapoint corresponds to a mean of 30-40 measurements (depending on the temperature) and its standard deviation. 
39 Figure 6: Effect of oxygen concentration on the EKG characteristics at $10^{\circ} \mathrm{C}$ 40 and under 80 bars (8 MPa) of pressure. Open diamonds: mean EKG amplitude

41 (25-35 measurements) and standard deviation. Black diamonds: heart rate (as a 42 percent of maximum to avoid overlap with the EKG amplitude symbols). The 43 boxed area corresponds to the oxygen range for which the heart rate already 44 drops while the amplitude of the EKG remains relatively constant.

45

46 Figure 7: Time series of recordings of heart rate, oxygen concentration, and 47 shape of the EKG (insets with 5-second recordings) at $20^{\circ} \mathrm{C}$ and under 80 48 bars (8 MPa) of pressure. Insets represent different characteristic times: before 49 hypoxic exposure (245 minutes), early in the pronounced hypoxic conditions 50 (310 minutes), after prolonged exposure to hypoxia (342 minutes), then 51 recovery (390 minutes), and finally after return to normal conditions (467 52 minutes). 
$54 \quad$ Figure 1

55 A
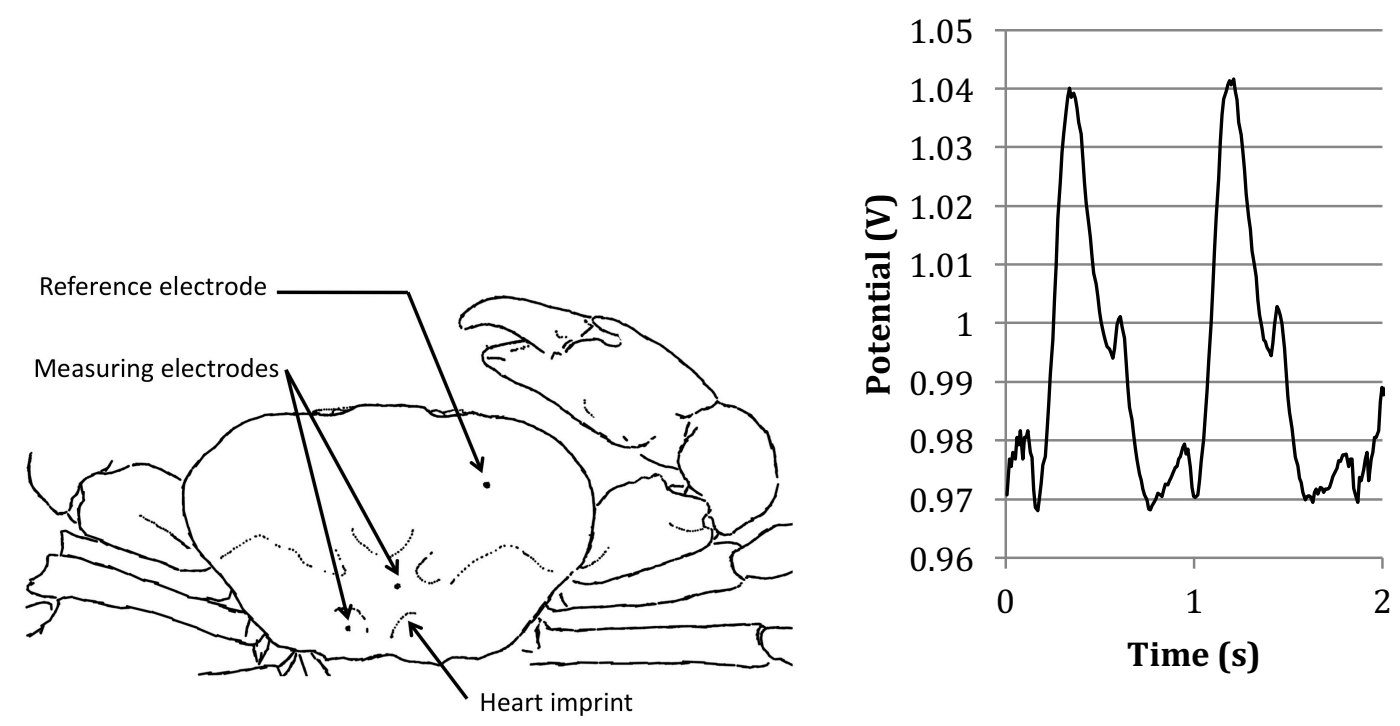

57 B

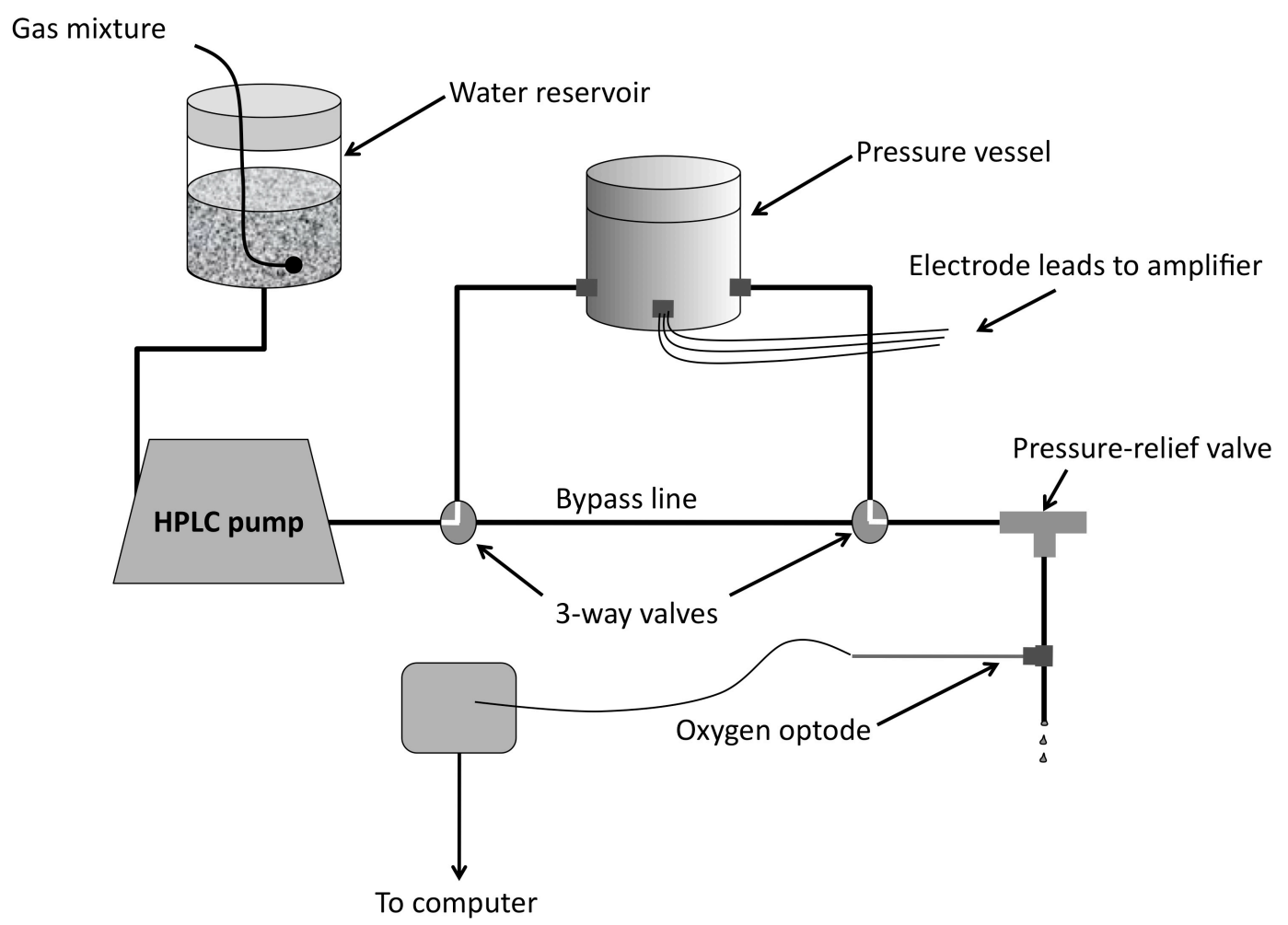

58

59 
$61 \quad$ Figure 2

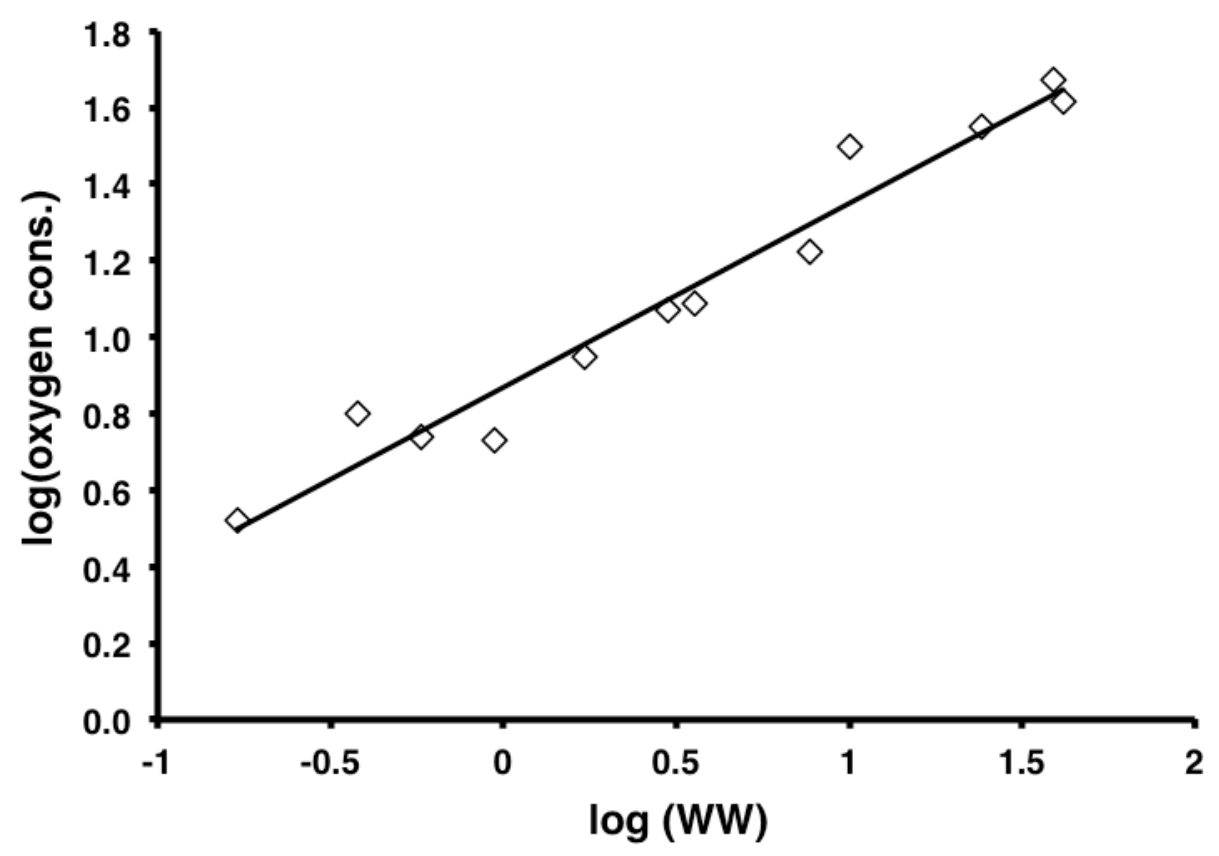

62

63 
Figure 3

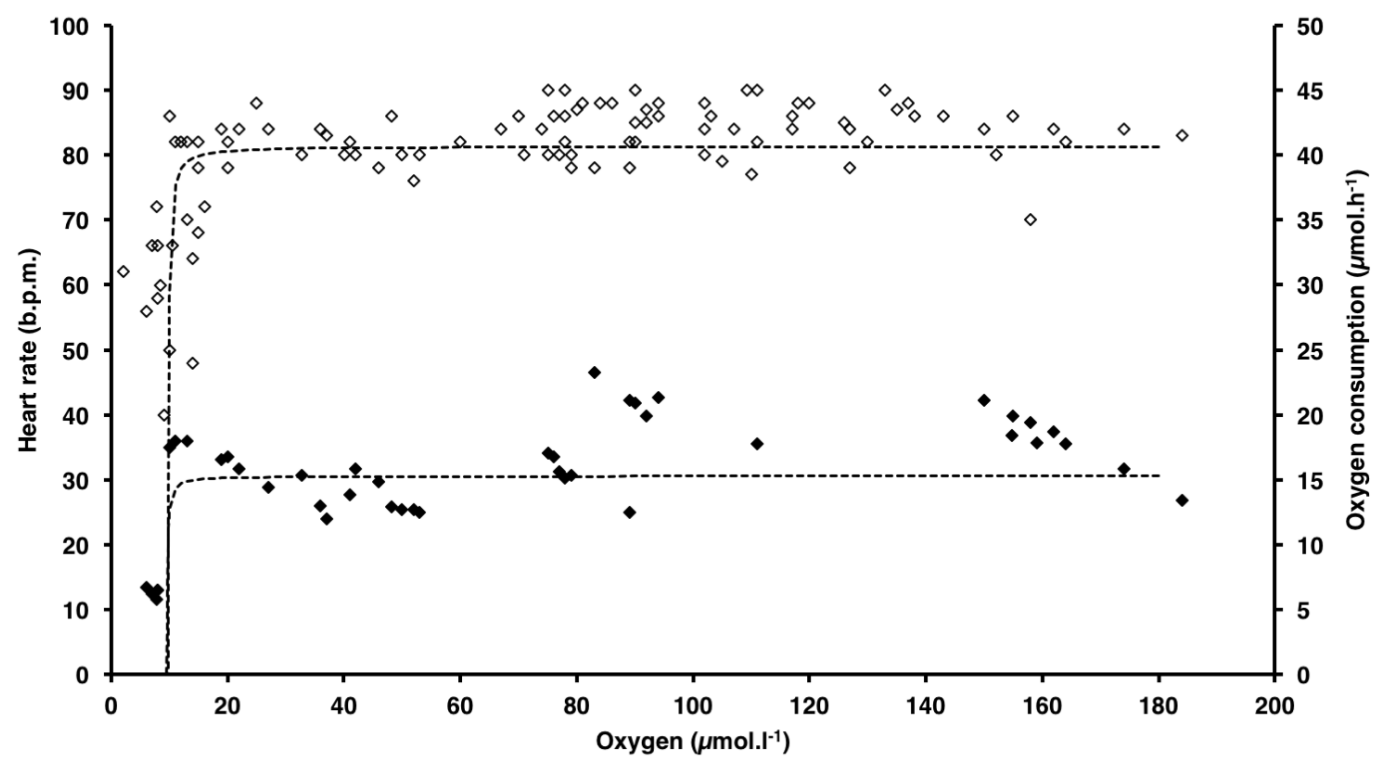

65

66 
Figure 4
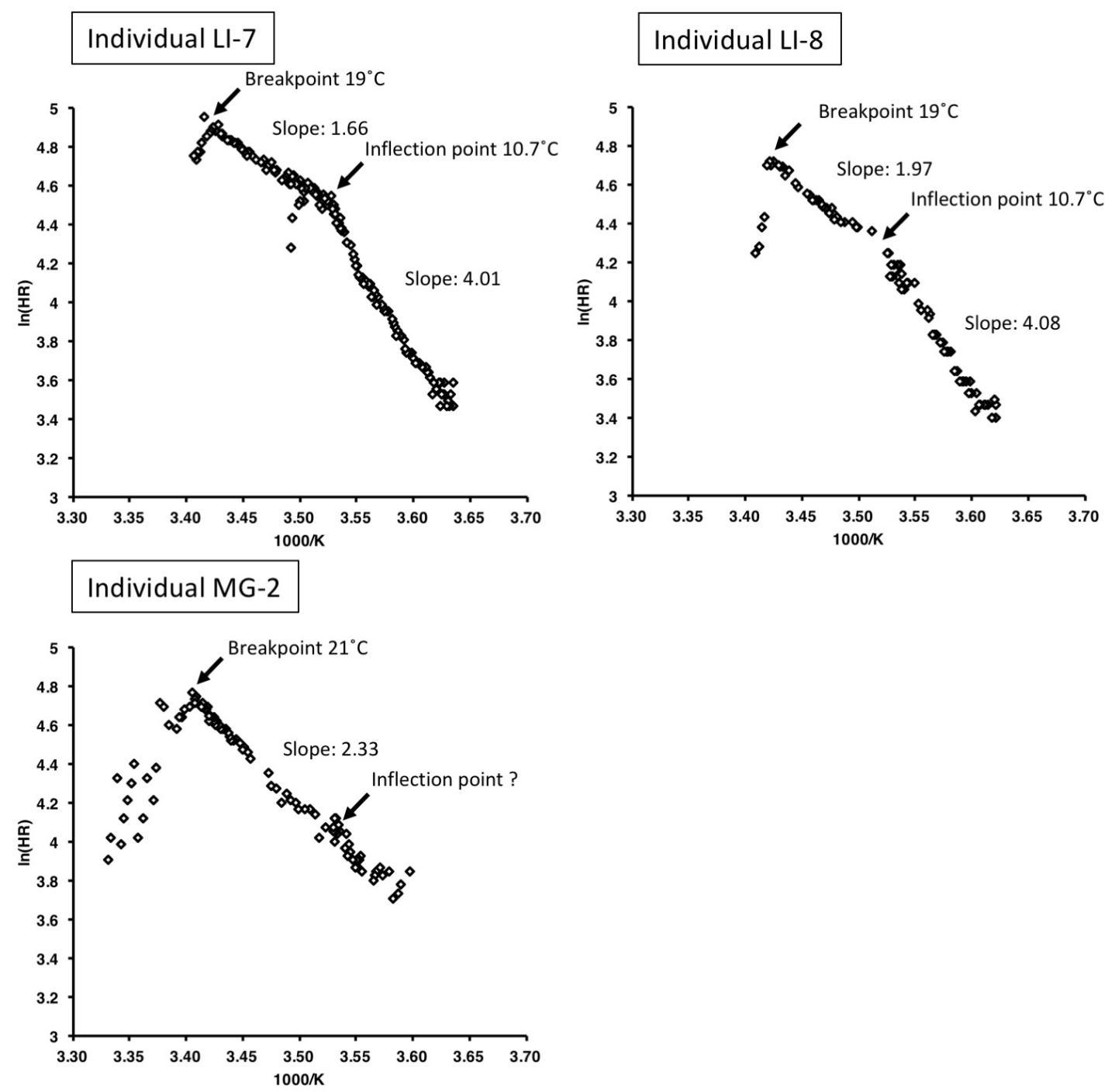
Figure 5
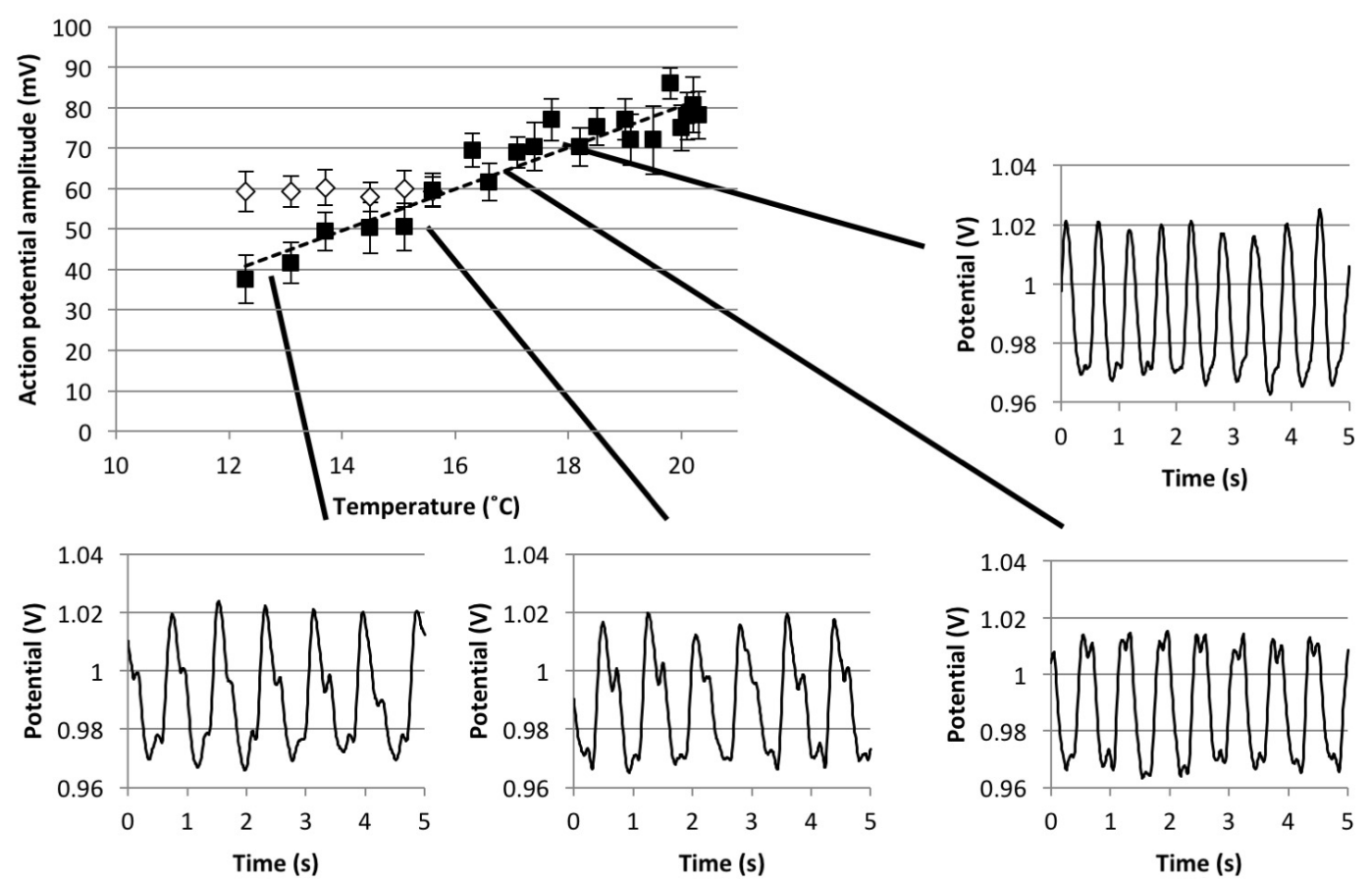
$74 \quad$ Figure 6

75

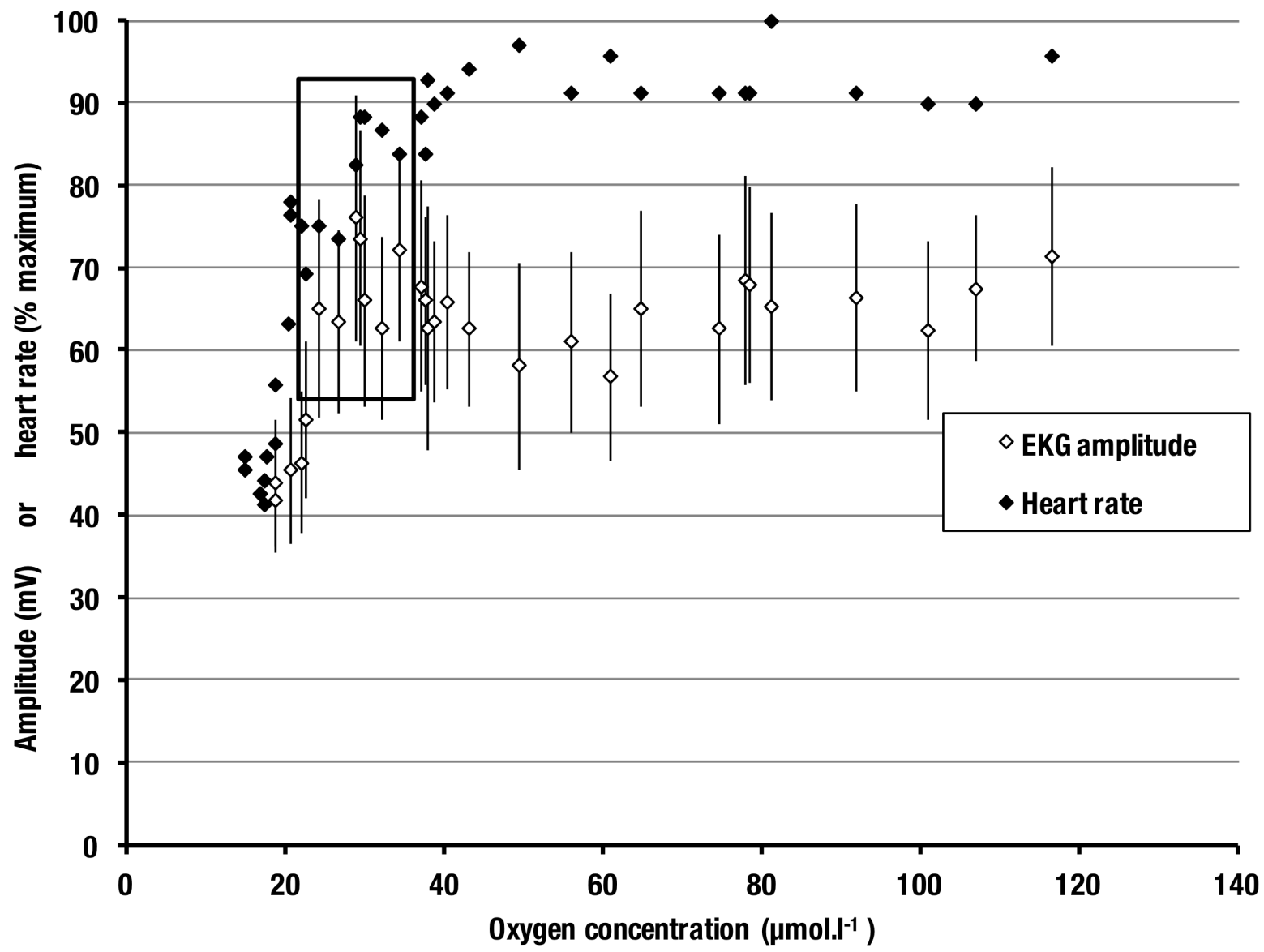

76 


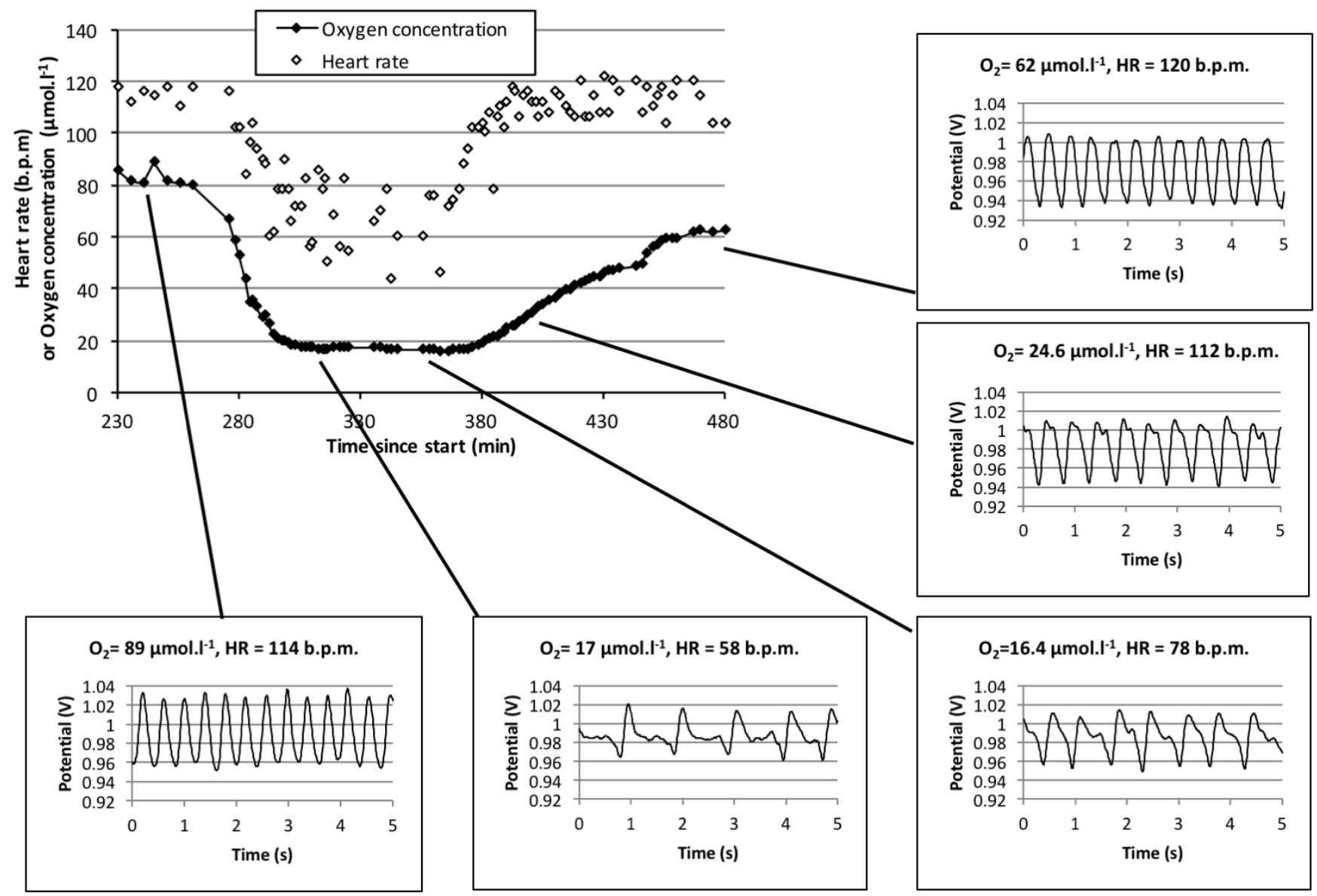

